\title{
Isolation of Bulk Amount of Piperine as Active Pharmaceutical Ingredient (API) from Black Pepper and White Pepper (Piper nigrum L.)
}

\author{
Zihan Rahman Khan', Fatema Moni', Suriya Sharmin'1, Muhammad Abdullah Al-Mansur², \\ Abdul Gafur ${ }^{3}$, Obaidur Rahman', Farhana Afroz ${ }^{*}$
}

\author{
${ }^{1}$ Pharmaceutical Sciences Research Division, BCSIR Laboratories, Dhaka, Bangladesh \\ ${ }^{2}$ Institute of National Analytical Research and Service (INARS), BCSIR, Dhaka, Bangladesh \\ ${ }^{3}$ Pilot Plant \& Process Development Center (PP \& PDC), BCSIR, Dhaka, Bangladesh \\ ${ }^{4}$ Department of Biology \& Chemistry, North South University, Dhaka, Bangladesh \\ Email: ${ }^{\star}$ farhana04@yahoo.com
}

How to cite this paper: Khan, Z.R., Moni, F., Sharmin, S., Al-Mansur, M.A., Gafur, A., Rahman, O. and Afroz, F. (2017) Isolation of Bulk Amount of Piperine as Active Pharmaceutical Ingredient (API) from Black Pepper and White Pepper (Piper nigrum L.). Pharmacology \& Pharmacy, 8, 253-262.

https://doi.org/10.4236/pp.2017.87018

Received: June 22, 2017

Accepted: July 28, 2017

Published: July 31, 2017

Copyright (C) 2017 by authors and Scientific Research Publishing Inc. This work is licensed under the Creative Commons Attribution International License (CC BY 4.0).

http://creativecommons.org/licenses/by/4.0/ (c) (7) Open Access

\begin{abstract}
In the pharmaceutical world the majority of the active pharmaceutical ingredients (API) have been obtained from the natural products. Piperine is such naturally occurring alkaloid which can be considered as major bioactive phytochemical having broad spectrum of pharmacological activities. It is obtained from the most valuable ethnomedicinal spices peppercorns i.e. black pepper and white pepper, which are the fruits of the Asian vine Piper nigrum L. Because of the widespread traditional uses of this medicinal compound, present article reveals a simple and effective isolation method of bulk piperine. The novelty of this investigation is to provide an idea for utilizing such natural method of large scale commercial piperine production as API drug in spite of chemical synthesis. Piperine was isolated in a pure crystal form and characterized by its melting point, X-Ray diffraction (XRD) studies and spectral data, including two-dimensional nuclear magnetic resonance (2D-NMR) spectroscopy. Chromatographic techniques like Thin Layer Chromatography (TLC) and High Performance Liquid Chromatography (HPLC) were applied to determine the purity of the yielded piperine. It was found that piperine yield from black pepper was within $2.5 \%-3.0 \%$ and from white pepper within $4.0 \%-4.5 \%$ and the purity of the yielded piperine was found to be up to $98.5 \%$ for black pepper and $98.2 \%$ for white pepper. Considering this yield value and purity it is indicated that, such effective isolation method can be successfully utilized for industrial large-scale production commercially. According to the result, it can be claimed that, as a natural product the isolated piperine can also be utilized as API drug like other expensive chemically synthesized piperine in different drug formulation.
\end{abstract}




\section{Keywords}

Piper nigrum L., NMR Spectroscopy, X-Ray Diffraction Studies, Bulk Piperine

\section{Introduction}

Piperine is the pungent chemical constituent that imparts an excellent medicinal value to pepper spices, most commonly used in folk medicine e.g. in "Trikatu", a classic ayurvedic herbal formulation containing different kinds of pepper spices like black pepper, long pepper etc. traditionally used to support digestion, the overall gastric function and also the respiratory function due to its strong pungent qualities caused by piperine [1]. Piperine has tremendous role in pharmacotherapeutics as it has been recognized as potential bioavailability enhancer by promoting rapid absorption and also having the effect on inhibiting metabolizing enzyme responsible for biotransformation of drugs or nutrients and thus preventing their inactivation and elimination [2] [3]. Piperine also possesses physiological effects like increased salivation, enhanced secretion of gastric juice which lead to better digestion and bioavailability of nutritional constituents [4]. Piperine is generally consumed through black pepper or white pepper and by using these peppers to our daily consuming meal is the convenient way to increase nutrient absorption and metabolism.

Piperine possesses a broad spectrum of pharmacological activities and it is mentioned through several experiments that piperine can be used as antioxidant, antibacterial, antifungal, anti-colon toxin, antidepressant, antidiarrhoeal, antiinflammatory, antimutagenic, anticancer, antispasmodic, insecticidal activity etc. [5]. It is reported that piperine has an antimicrobial effect and thus protects the seeds in which it is placed from the attack of microbes [6]. Having this antimicrobial activity of piperine, pepper spices were traditionally used in folk medicine for the treatment of many respiratory infectious diseases such as cough, bronchitis, tonsillitis, sinusitis, tuberculosis etc. and also some Gastrointestinal Tract (GIT) disorder like gastritis, peptic ulcers etc. [7] [8]. Due to these remarkable biological roles, researchers are now regarded piperine as a valuable natural bio-active compound and day by day new research is documenting many health benefits regarding of piperine.

Natural products have played a key role in pharma research, as many medicines are either natural products or derivatives thereof [9]. Modern chemistry has ushered in a new era for the study and use of natural products. Analytical and structural chemistry have provided the tools to purify various compounds and to determine their structures, which, in turn, has given insights into their action on the human body. The structural analysis of natural compounds and the ability to synthesize them allowed chemists to modify these compounds in order to suppress or enhance certain characteristics such as solubility, efficiency or stability in the human body [10] [11]. But, many non-natural, synthetic drugs 
cause several side effects that were not acceptable and sometimes it is difficult to synthesize structurally complex metabolites; which can be overcome by the use of metabolites discovered in medicinal plants and other natural products [12]. The present study was aimed to isolate piperine in a pure form from these natural sources like black pepper and white pepper indigenous to Bangladesh in a bulk amount to be used in drug formulation as an API.

\section{Materials and Methods}

\subsection{Instrumentation}

The extract was condensed in rotary vacuum evaporator (Heidolph Instruments GmbH \& Co. KG, Germany). Melting point was determined on Stuart melting point apparatus SMP30 (UK). Crystalline structure was observed by XRD study (D8 Advance, BRUKER, Germany). NMR spectra were recorded on Bruker WP AM 400 spectrometer (Switzerland). For purity analysis Hitachi HPLC system equipped with La-chrome $\mathrm{C}_{18}$ column $(5 \mu \mathrm{m}, 4.6 \mathrm{~mm} \times 250 \mathrm{~mm})$ and UVGL-58 Handheld UV Lamp (UK) was used for TLC analysis.

\subsection{Chemicals and Reagents}

Black pepper and white pepper were purchased from a local retail market. Potassium hydroxide (Calbiochem, Merck, Germany) and $\mathrm{CDCl}_{3}$ (Sigma-Aldrich, USA) were used in this study. All other chemicals were purchased from Active Fine Chemicals Ltd., Bangladesh.

\subsection{Isolation and Purification}

The black pepper and white pepper fruits were washed, dried and mechanically reduced to coarse powder form. $100 \mathrm{~g}$ of dried powder of black pepper and white pepper was successively extracted to exhaustion in a soxhlet using $400 \mathrm{ml}$ of $95 \%$ ethanol. For condensing the extract, the solvent was evaporated on the rotary evaporator where we can get the oleoresin, the true essence of spices. From the concentrated extracts yellow colored needles were formed which were collected through filtration and from the remaining filtrate the crystals were isolated by deresinification with $10 \%$ alcoholic $\mathrm{KOH}$ solution through the precipitation with water which was further collected by filtration. In order to get the compound in a more pure form the isolated crystals were recrystallized by dissolving in a dichloromethane where few drops of $\mathrm{n}$-Hexane was applied and allowed the solution to settle undisturbed for few hours. Rod-like, light yellow crystals were formed which were collected through filtration and purified by treatment with solvent mixture (n-Hexane/1\% Dichloromethane) to remove the undesired components. Finally, the resulting crystals were weighed to know the exact yield.

\subsection{Characterization of the Isolated Compound}

The isolated compound 1 was characterized by its melting point, XRD studies and spectral data including 2D-NMR. 


\subsubsection{Melting Point Studies}

Piperine can be characterized by its melting point which is within range of $129^{\circ} \mathrm{C}-130^{\circ} \mathrm{C}$ [12]. In the present study the melting point of the compound 1 from both of black pepper and white pepper were determined.

\subsubsection{XRD Studies}

XRD studies of powdered crystals were carried out to study crystalline nature of the isolated compound 1 from both of black pepper and white pepper.

\subsubsection{NMR Spectra Studies}

NMR spectra were recorded $\left({ }^{1} \mathrm{H}\right.$ at $400 \mathrm{MHz}$ and ${ }^{13} \mathrm{C}$ at $\left.100 \mathrm{MHz}, \mathrm{CDCl}_{3}\right)$ for the isolated compound 1 obtained from both of black pepper and white pepper to elucidate the structure and chemical shifts were reported in ppm.

\subsection{Purity Analysis of the Isolated Piperine}

Chromatographic techniques like TLC and HPLC were applied to determine the purity of the isolated piperine.

\subsubsection{TLC Analysis}

Thin layer chromatographic technique was used for the initial screening of the extracts and checking the purity of isolated compound using toluene/20\% ethyl acetate and visualized under UV light at $254 \mathrm{~nm}$ and $365 \mathrm{~nm}$.

\subsubsection{HPLC Analysis}

Piperine obtained from both of black pepper and white pepper was dissolved in methanol to obtain a concentration of approximately $0.2 \mathrm{mg} / \mathrm{ml}$. The samples were analyzed by a Hitachi HPLC system with UV visible detector. The mobile phase consists of acetonitrile, water and acetic acid at ratio of 60:39.5:0.05 and 1 $\mathrm{ml} / \mathrm{min}$ flow rate. $10 \mu \mathrm{l}$ of sample was injected into the column at ambient temperature. Chromatogram was monitored at $340 \mathrm{~nm}$. Peak area for piperine was observed at retention time of approximately $8.55 \mathrm{~min}$. Purity of piperine was calculated by area percent method.

\section{Results}

\subsection{Quantification of the Isolated Compound}

The content of the isolated compound 1 in $100 \mathrm{~g}$ raw materials were found to be higher in white pepper $(4.1 \mathrm{~g})$ compared to black pepper $(2.9 \mathrm{~g})$.

\subsection{Characterization of the Isolated Compound}

\subsubsection{Melting Point Studies}

The compound 1 was characterized by its melting point which showed that it undergoes melting at $129^{\circ} \mathrm{C}$ for white pepper and at $130^{\circ} \mathrm{C}$ for black pepper which is close to the standard range $\left(129^{\circ} \mathrm{C}-130^{\circ} \mathrm{C}\right)[12]$.

\subsubsection{XRD Studies}

Structural properties of the isolated compound 1 from both of black pepper and 
white pepper were investigated by XRD with $\operatorname{CuK} \alpha(\lambda=1.54)$ radiation and $2 \theta$ ranges from $4^{\circ}$ to $60^{\circ}$. The XRD pattern of the compound 1 (Figure 1) reveals that the pattern matched with the standard pattern of piperine (JCPDS Card no: 00-043-1627) and its chemical formula $\mathrm{C}_{17} \mathrm{H}_{19} \mathrm{NO}_{3}$ having monoclinic structure (space group: P21/n (14), a $=8.69500 \mathrm{~A}^{\circ}, \mathrm{b}=13.60200 \mathrm{~A}^{\circ}, \mathrm{c}=13.15800 \mathrm{~A}^{\circ}, \mathrm{z}$ $=4)$.

\subsubsection{NMR Spectra Studies}

The compound 1 was assigned piperine (Figure 2) by $1 \mathrm{D}$ - and 2D-NMR spectroscopic methods. The ${ }^{13} \mathrm{C}$ NMR spectrum $\left(100 \mathrm{MHz}, \mathrm{CDCl}_{3}\right.$ ) of 1 displayed 17 carbon resonances, while HSQC experiment indicated that 13 out of 17 carbons were attached to proton. ${ }^{1} \mathrm{H}$ NMR $\left(400 \mathrm{MHz}, \mathrm{CDCl}_{3}\right)$ and DEPT $135(100 \mathrm{MHz}$, $\mathrm{CDCl}_{3}$ ) spectraof 1 revealed the presence of five methylene groups which belongs to the piperidine ring, a methylene dioxy group and seven olefinic/aromatic methines of which three are aromatics and four are olefinics. The ${ }^{1} \mathrm{H} N M R$ and ${ }^{13} \mathrm{C}$ NMR chemical shifts are shown in Table 1.

The resonances at $\delta=3.62 \mathrm{ppm}$ and $3.51 \mathrm{ppm}$ in the ${ }^{1} \mathrm{H}$ NMR and $\delta=43.3$ ppm and $46.9 \mathrm{ppm}$ in the ${ }^{13} \mathrm{C}$ NMR spectra, in conjunction with the DEPT 135 spectrum could be attributed for the hydrogens and carbons [Pip-(2) and Pip(6), respectively] of the piperidine ring, which are next to the nitrogen. The resonances at $\delta=1.58 \mathrm{ppm}, 1.65 \mathrm{ppm}$ and $1.58 \mathrm{ppm}$ in the ${ }^{1} \mathrm{H}$ NMR and $\delta=26.8$ ppm, $24.7 \mathrm{ppm}$ and $25.7 \mathrm{ppm}$, respectively, in the ${ }^{13} \mathrm{C}$ NMR spectra, in conjunction

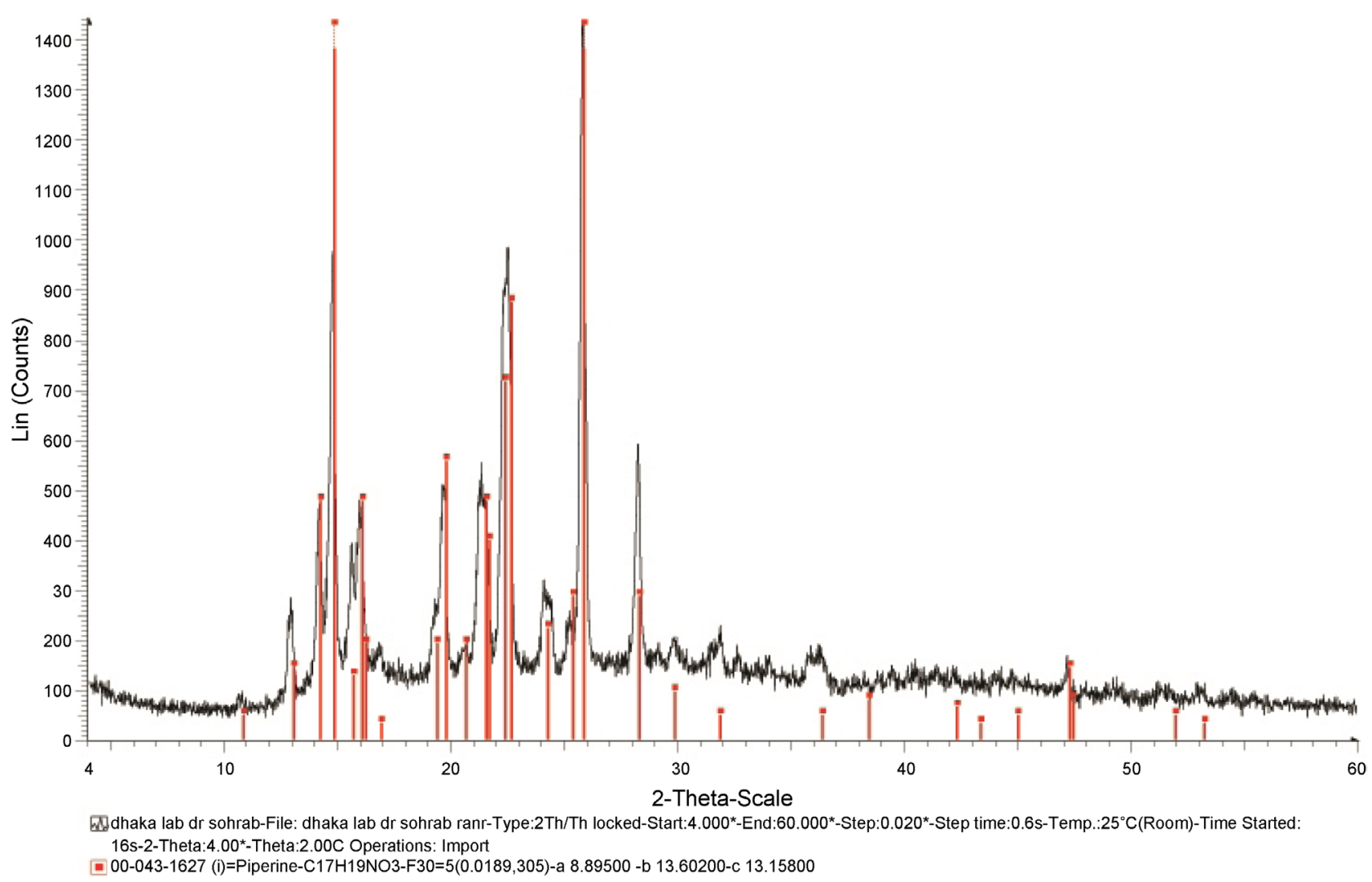

Figure 1. X-ray diffractogram of compound 1. 
(a)

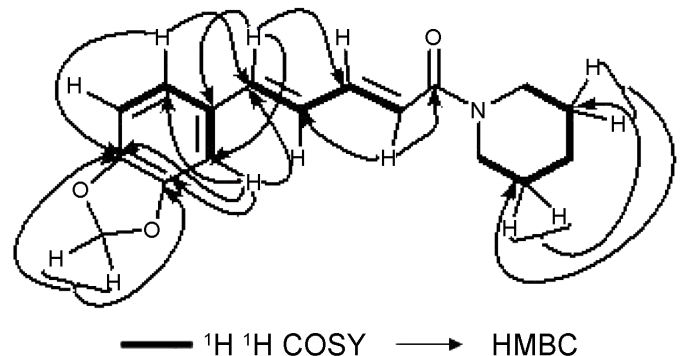

(b)

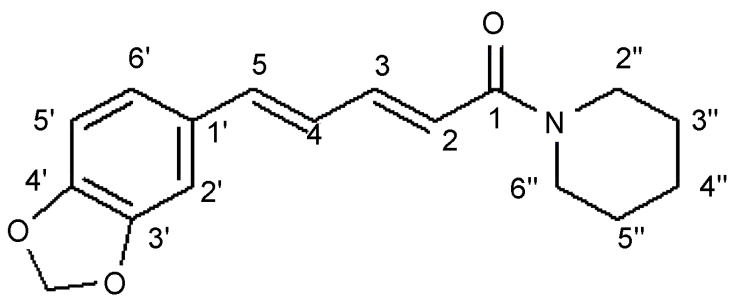

BP-1

Figure 2. (a) connectivities of 1 and (b) structure of 1 .

Table 1. ${ }^{1} \mathrm{H}\left(400 \mathrm{MHz}, \mathrm{CDCl}_{3}\right)$ and ${ }^{13} \mathrm{C}\left(100 \mathrm{MHz}, \mathrm{CDCl}_{3}\right) \mathrm{NMR}$ data for compound 1.

\begin{tabular}{|c|c|c|c|c|c|c|}
\hline \multirow{2}{*}{ Position } & \multicolumn{4}{|c|}{1} & \multicolumn{2}{|l|}{ Piperine [13] } \\
\hline & $\delta_{\mathrm{H}}$ (mult., Jin Hz) & $\delta_{\mathrm{C}}$ & $\operatorname{cosy}$ & HMBC & $\delta_{\mathrm{H}}$ (mult., $J$ in $\mathrm{Hz}$ ) & $\delta_{\mathrm{C}}$ \\
\hline 1 & --- & 165.5 & --- & --- & --- & 165.6 \\
\hline 2 & $6.42, \mathrm{~d}, J=14.8 \mathrm{~Hz}$ & 120.1 & $\mathrm{H} 3$ & $\mathrm{C} 1, \mathrm{C} 4$ & $6.38, \mathrm{~d}, J=14.7 \mathrm{~Hz}$ & 119.7 \\
\hline 3 & 7.38, ddd, $J=14.3,8.4,1.8 \mathrm{~Hz}$ & 142.5 & $\mathrm{H} 2, \mathrm{H} 4$ & - & 7.36, ddd, $J=14.7,8.3,1.9 \mathrm{~Hz}$ & 142.8 \\
\hline 4 & $6.74, \mathrm{~m}$ & 125.4 & $\mathrm{H} 3$ & $\mathrm{C} 3, \mathrm{C} 1^{\prime}$ & overlapping & 125.2 \\
\hline 5 & $6.74, \mathrm{~m}$ & 138.2 & $\mathrm{H} 3$ & $\mathrm{C} 3, \mathrm{C} 1{ }^{\prime}, \mathrm{C} 2{ }^{\prime}$ & overlapping & 138.4 \\
\hline $1^{\prime}$ & & 131.1 & - & - & --- & 130.9 \\
\hline $2^{\prime}$ & $6.96, s$ & 105.7 & $\mathrm{H}^{\prime}$ & $\mathrm{C} 5, \mathrm{C} 3{ }^{\prime}, \mathrm{C} 4{ }^{\prime}, \mathrm{C} 6^{\prime}$ & $6.93, \mathrm{~d}, J=1.5 \mathrm{~Hz}$ & 105.6 \\
\hline $3^{\prime}$ & --- & 148.2 & - & --- & --- & 148.06 \\
\hline $4^{\prime}$ & --- & 148.1 & - & --- & --- & 148.09 \\
\hline $5^{\prime}$ & $6.76, \mathrm{~d}, J=8.0 \mathrm{~Hz}$ & 108.5 & $\mathrm{H} 6^{\prime}$ & $\mathrm{C} 1, \mathrm{C} 3{ }^{\prime}, \mathrm{C} 4^{\prime}$ & overlapping & 108.4 \\
\hline $6^{\prime}$ & $6.88, \mathrm{~d}, J=8.0 \mathrm{~Hz}$ & 122.5 & $\mathrm{H} 2{ }^{\prime}, \mathrm{H} 5^{\prime}$ & $\mathrm{C} 5, \mathrm{C} 2{ }^{\prime}, \mathrm{C} 4^{\prime}$ & $6.84, \mathrm{dd}, J=6.0,1.5 \mathrm{~Hz}$ & 122.5 \\
\hline Methylenedioxy & $5.96, s$ & 101.3 & - & $\mathrm{C} 3{ }^{\prime}, \mathrm{C} 4^{\prime}$ & $5.9, \mathrm{~s}$ & 101.2 \\
\hline $2 "$ & $3.62, \mathrm{~m}$ & 43.3 & H3 " & --- & 3.48 , brs & 43.3 \\
\hline $3 "$ & $1.58, \mathrm{~m}$ & 26.8 & $\mathrm{H} 2$ ", $\mathrm{H} 4 "$ & C5 & $1.54, \mathrm{~m}$ & 26.6 \\
\hline $4 "$ & $1.65, \mathrm{~m}$ & 24.7 & H3", H5 " & --- & $1.54, \mathrm{~m}$ & 24.5 \\
\hline $5 "$ & $1.58, \mathrm{~m}$ & 25.7 & $\mathrm{H} 4$ ", H6" & C3" & $1.54, \mathrm{~m}$ & 25.5 \\
\hline $6^{\prime \prime}$ & $3.51, \mathrm{~m}$ & 46.9 & H5" & & 3.57, brs & 46.9 \\
\hline
\end{tabular}

with the DEPT 135 spectrum could be attributed for the other methylene protons in the piperidine ring [Pip-(3), Pip-(4) and Pip-(6), respectively]. The singlet at $\delta=5.96 \mathrm{ppm}$ in the ${ }^{1} \mathrm{H}$ NMR and at $\delta=101.3 \mathrm{ppm}$ in the ${ }^{13} \mathrm{C}$ NMR spectra, in conjunction with the DEPT 135 spectrum could be attributed for methylene- 
dioxy of dioxolane ring. The resonances at $\delta=165.5 \mathrm{ppm}$ in the ${ }^{13} \mathrm{C}$ NMR spectrum was characteristic for the presence of the amide carbonyl atom.

The most deshielded signal at $\delta=7.38 \mathrm{ppm}$ in the ${ }^{1} \mathrm{H}$ NMR spectrum could be assigned to $\mathrm{H}-3$, as its chemical shifts is typical for $\beta$-proton in $\alpha / \beta$-unsaturated carbonyl compounds. The sharp doublet at $\delta=6.42 \mathrm{ppm}$ with the spin coupling of $14.8 \mathrm{~Hz}$ in the ${ }^{1} \mathrm{H}$ NMR spectrum could be assigned to $\mathrm{H}-2$. The singlets at $\delta=$ $6.96 \mathrm{ppm}$, doublets at $\delta=6.76 \mathrm{ppm}(J=8 \mathrm{~Hz})$ and $6.88 \mathrm{ppm}(J=8 \mathrm{~Hz})$ in the ${ }^{1} \mathrm{H}$ NMR spectra constitute the very typical pattern of a $1,2,4$-trisubstituted aromatic compound.

Analysis of one- and two-dimensional NMR spectra including COSY, HSQC and $\mathrm{HMBC}$ led to the assignment of structure "a" (Figure 2). In this structure, the C2-C3-C4-C5 portion, $\mathrm{C} 2$ '- C1 $^{\prime}-\mathrm{C} 6$ '-C5 ' portion and $\mathrm{C} 2$ "-C3"-C4"-C5"-C6" portion were assigned by tracing of cross peaks in COSY spectrum. The structure of piperine (Figure 2) was disclosed by HMBC correlations (H-2/C-1; $\mathrm{H}-2 / \mathrm{C}-4 ; \mathrm{H}-5 / \mathrm{C}-3$; H-5/C-2 ; H-5/C-1; H-2 /C-5; H-2 /C-6; H-2 /C-3; H-2 /C-4; H-6'/C-4'; H-6'/C-5';

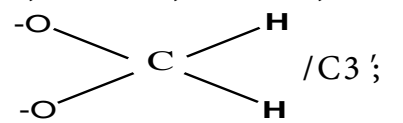<smiles>[CH2][C@H]([O-])[C@@H]([CH2])[O-]</smiles>
$\mathrm{H} 3$ "/C5"; H5 "/C3") in 1.

The ${ }^{1} \mathrm{H}$ NMR and ${ }^{13} \mathrm{C}$ NMR data of 1 was found to be identical to those reported previously for the piperine [13] [14].

\subsection{Purity Analysis of the Isolated Piperine}

\subsubsection{TLC Analysis}

During primary purity screening of the isolated piperine, it was appeared as a dark quenching spot on the TLC plate $\left(\mathrm{R}_{f}=0.5\right.$, toluene $/ 20 \%$ ethyl acetate $)$ under UV light at $254 \mathrm{~nm}$ and blue fluorescent spot at $365 \mathrm{~nm}$.

\subsubsection{HPLC Analysis}

Purity of the isolated piperine was determined by HPLC. Area percent method was used for calculation where major peak at retention time 8.55 min was considered as the peak of piperine (Figure 3). Piperine yield from black pepper was $2.5 \%-3.0 \%$ and from white pepper $4.0 \%-4.5 \%$ complying with the previous report [15]. Purity of the yielded piperine found to be up to $98.5 \%$ and $98.2 \%$ obtained from black pepper and white peeper respectively (Table 2 ).

\section{Discussion}

Currently in spite of the presence of huge available synthetic drug materials, many pharmaceutical companies are now focused on the development of plantderived active ingredients in order to avoid the costs and complexities. In fact, around $50 \%$ of pharmaceuticals are derived from compounds first identified or isolated from herbs/plants, including organisms, animals, and insects, as active ingredients e.g. Artemisinin, Taxol, Vincristine etc. These naturally obtained drugs are now attempted to be isolated in bulk amount for the development of newly approved therapeutic agents as API [16]. Piperine is the naturally occurring 


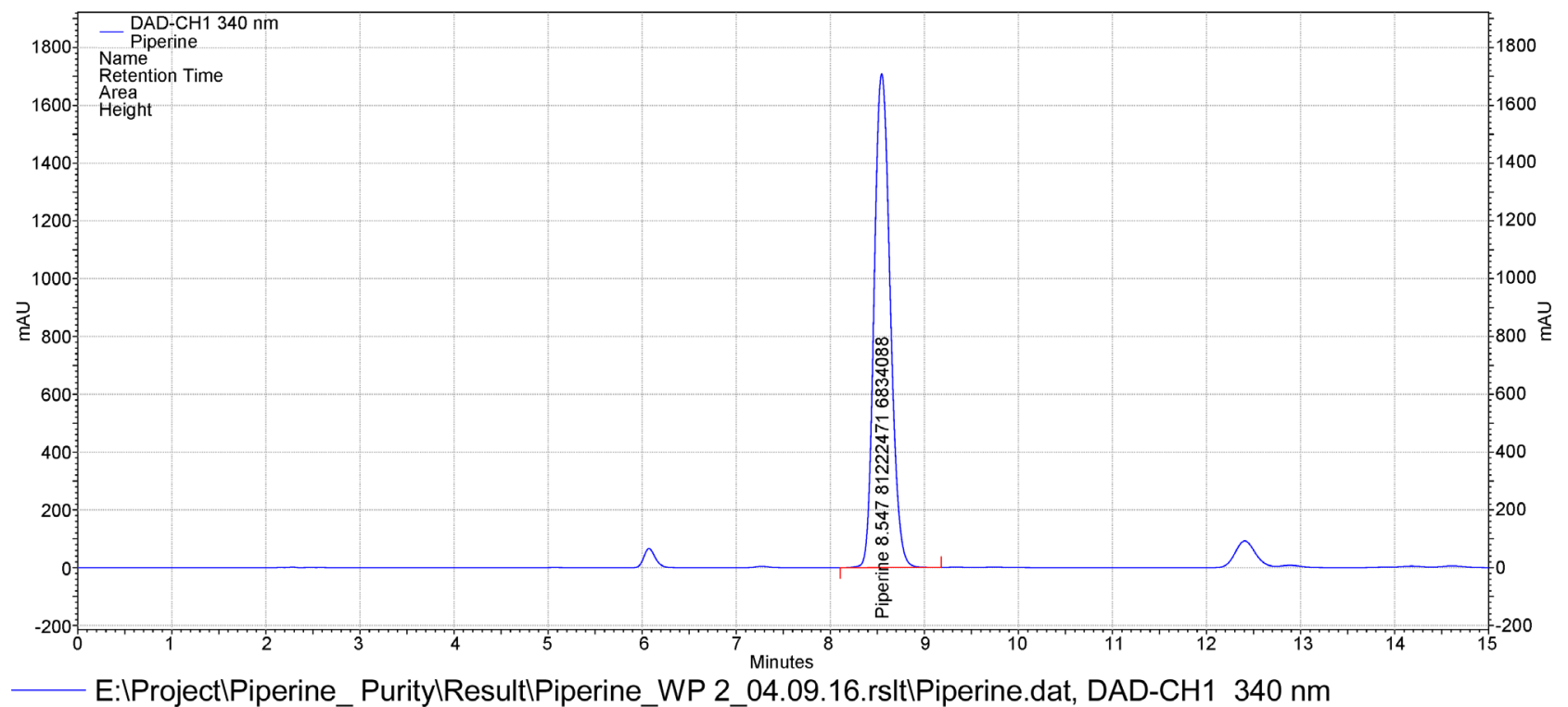

Figure 3. HPLC chromatogram of isolated piperine.

Table 2. Purity of the yielded piperine from black pepper and white pepper.

\begin{tabular}{ccc}
\hline Source & Yield (\%) & Purity (\%) \\
\hline Black pepper & 2.9 & 98.5 \\
White pepper & 4.1 & 98.2 \\
\hline
\end{tabular}

alkaloid considered as the most desirable therapeutic agent obtained from the piper spices which imparts pungency and medicinal values of that spices. In present work a short and effective method was developed to isolate bulk piperine from these natural pepper spices i.e. black pepper and white pepper to formulate as API.

Piperine was successfully isolated in a pure crystal form and that isolated crystals were characterized by its melting point which showed within the standard range $\left(129^{\circ} \mathrm{C}-130^{\circ} \mathrm{C}\right)$ indicating no impurities and were used for further phytohemical screening. While determining Structural properties, XRD pattern of the isolated compound matched with the standard pattern of piperine (Figure 1) and structure of piperine was confirmed as that of piperine (Figure 2) by 1Dand 2D-NMR spectroscopic methods. Analysis of isolated piperine by HPLC revealed its purity $98.5 \%$ and $98.2 \%$ obtained from black pepper and white pepper respectively, with a good yield value of $2 \%-5 \%$ and considering the purity that was the acceptable range of the yield value of the isolated piperine to be claimed as API.

\section{Conclusion}

According to the literature reviews, piperine can be considered as the already established bioactive compound [5]. So following purity analysis it can be claimed that, the active pharmaceutical activity of the extracted piperine in the work will find to be similar like other expensive synthetic piperine. In that case, 
a comparative bioactivity screening between naturally and chemically synthesized piperine can be investigated in future. Finally, it can be concluded that the isolation method applying in this study can be successfully followed for the commercial production of bulk piperine to be utilized as API.

\section{Acknowledgements}

ZRK gratefully acknowledges BCSIR for awarding Prof. MafizUddin Ahmed Smrity Fellowship and providing laboratory facilities at Pharmaceutical Sciences Research Division (PSRD), BCSIR Laboratories, Dhaka.

\section{Competing Interests}

The authors declare that they have no competing interests.

\section{References}

[1] Johri, R.K. and Zutshi, U. (1992) Anayurvedic Formulation "Trikatu” and Its Constituents. Journal of Ethnopharmacology, 37, 85-91. https://doi.org/10.1016/0378-8741(92)90067-2

[2] Dudhatra, G.B., Mody, S.K., Awale, M.M., Patel, H.B., Modi, C.M., Kumar, A., et al. (2012) A Comprehensive Review on Pharmacotherapeutics of Herbal Bioenhancers. The Scientific World Journal, 2012, 338-345. https://doi.org/10.1100/2012/637953

[3] Ajazuddin, Alexander, A., Qureshi, A., Kumari, L., Vaishnav, P., Sharma, M., Saraf, S., et al. (2014) Role of Herbal Bioactives as a Potential Bioavailability Enhancer for Active Pharmaceutical Ingredients. Fitoterapia, 97, 1-14. https://doi.org/10.1016/j.fitote.2014.05.005

[4] Lijing, C., Jiawen, L., Lanlin, L., Shaolin, Y., Jian, Y., Qizhi, Z., et al. (2014) Effect of Piperine on Metabolism and Distribution of Nortriptyline in Mice. Journal of Central South University of Technology, 39, 349-354.

[5] Ahmad, N., Fazal, H., Abbasi, B.H., Farooq, S., Ali, M. and Khan, M.A. (2012) Biological Role of Piper nigrum L. (Black Pepper): A Review. Asian Pacific Journal of Tropical Biomedicine, 5, 1945-1953. https://doi.org/10.1016/S2221-1691(12)60524-3

[6] Shiva Rani, S.K., Saxena, N. and Udaysree, N. (2013) Antimicrobial Activity of Black Pepper (Piper nigrum L.). Global Journal of Pharmacology, 7, 87-90.

[7] Srinivasan, K. (2007) Black Pepper and Its Pungent Principle-Piperine: A Review of Diverse Physiological Effects. Critical Reviews in Food Science and Nutrition, 47, 735-748. https://doi.org/10.1080/10408390601062054

[8] Vasavirama, K. and Upender, M. (2014) Piperine: A Valuable Alkaloid from Piper Spices. International Journal of Pharmacy and Phaarmaceutical Science, 6, 34-38.

[9] Lahlou, M. (2013) The Success of Natural Products in Drug Discovery. Pharmacology \& Pharmacy, 4, 17-31. https://doi.org/10.4236/pp.2013.43A003

[10] Ji, H.F., Li, X.J. and Zhang, H.Y. (2009) Natural Products and Drug Discovery. Can Thousands of Years of Ancient Medical Knowledge Lead us to New and Powerful Drug Combinations in the Fight against Cancer and Dementia? EMBO Reports, 10, 194-200. https://doi.org/10.1038/embor.2009.12

[11] Newman, D.J. (2008) Natural Products as Leads to Potential Drugs: An Old Process or the New Hope for Drug Discovery? Journal of Medicinal Chemistry, 51, 25892599. https://doi.org/10.1021/jm0704090 
[12] Kolhe, S.R., Borole, P. and Patel, U. (2011) Extraction and Evaluation of Piperine from Piper nigrum Linn. International Journal of Applied Biology and Pharmaceutical Technology, 2, 144-149.

[13] Dagli, S. (2004) Piperchaba and Its Chemical Constituents. KSU. Journal of Science and Engineering, 7, 34-37.

[14] Mohanraj, V., Aravindan, B., Jayaprakash, C. and Thenmozhi, M. (2014) Insilico Drug Design and Extraction of Piperine an Inhibitor for Fernesyltransferase in Cryptococcus neoformans. World Journal of Pharmaceutical Research, 3, 11071120.

[15] Madhavi, B.B., Nath, A.R., Banji, D., Madhu, M.N., Ramalingam, R. and Swetha, D. (2009) Extraction, Identification, Formulation and Evaluation of Piperine in Alginate Beads. Internationals Journal of Pharmacy and Phaarmaceutical Science, 1, 156-161.

[16] Pan, S.Y., Zhou, S.F., Gao, S.H., Yu, Z.L., Zhang, S.F., Tang, M.K., et al. (2013) New Perspectives on How to Discover Drugs from Herbal Medicines: CAM's Outstanding Contribution to Modern Therapeutics. Evidence-Based Complementary and Alternative Medicine, 13, 1-25. https://doi.org/10.1155/2013/627375

\section{Abbreviations}

JCPDS: Joint Committee on Powder Diffraction Standard; HSQC: Heteronuclear Single-Quantum Correlation; $\mathrm{MHz}$ : megahertz; $\mathrm{CDCl}_{3}$ : Deuterated chloroform; DEPT: Distortionless enhancement by polarization transfer; ppm: parts per million; HMBC: Heteronuclear Multiple Bond Correlation; COSY: Correlation spectroscopy.

Submit or recommend next manuscript to SCIRP and we will provide best service for you:

Accepting pre-submission inquiries through Email, Facebook, LinkedIn, Twitter, etc. A wide selection of journals (inclusive of 9 subjects, more than 200 journals)

Providing 24-hour high-quality service

User-friendly online submission system

Fair and swift peer-review system

Efficient typesetting and proofreading procedure

Display of the result of downloads and visits, as well as the number of cited articles

Maximum dissemination of your research work

Submit your manuscript at: http://papersubmission.scirp.org/

Or contact pp@scirp.org 